Espacio, Tiempo y Forma, Serie $N, H^{\text {a }}{ }^{\text {Moderna, } t .7, ~ 1994, ~ p a ́ g s . ~ 435-446 ~}$

\title{
Aproximación a un análisis de las técnicas de construcción del Puerto de Refugio de Las Palmas $(1883-1903)$
}

\author{
juan francisco Martín del Castillo
}

Se ha escrito mucho sobre los condicionantes políticos que motivaron, primero, el reclamo de una mayor preocupación por las infraestructuras de transportes en las Islas Canarias, y después, la reivindicación popular, auspiciada desde sectores claramente mercantiles o propiamente burgueses, de una gran obra portuaria para la Gran Canaria ${ }^{1}$, isla necesitada desde finales del siglo XVIII de un puerto seguro y accesible por mar a todo tipo de embarcaciones. Ya en aquel tiempo, en el que lo único existente era una pobre y ruinosa construcción a la altura de la ermita de San Telmo, llamado por todos el "Desembarcadero de Las Palmas" ${ }^{2}$, se

1 Cfr. Quintana NavarRo, Francisco, «La Luz, estación carbonera y despegue portuario, 1883-1913", Aguayro, n. 146 (mayo-abril de 1983), págs. 10-18; idem, Barcos negocios y burgueses en el Puerto de La LUz (1883-1913).Las Palmas: CIES (Cuadernos Canarios de Ciencias Sociales, n. ${ }^{19}$ ), 1985 (Memoria de licenciatura); idem, Pequeña Historia del Puerto de Refugio de La Luz, Las Palmas: Mancomunidad de Cabildos 1985; MoRAles LEzCANO, Víctor y QuintanA NAVARRo, FCo., “La Luz, puerto de escala internacional: 1852-1902», en V Coloquio de Historia Canario-Americana / Coloquio Internacional de Historia Marítima (1982). Las Palmas 1985; MARtín Galán, F., La formación de Las Palmas: Ciudad y Puerto (cinco siglos de evolución). Las Palmas: Junta del Puerto de La Luz y Las Palmas, Gobierno de Canarias, Cabildo Insular de Gran Canaria y Ayuntamiento de Las Palmas, 1984; Herrera PIQué, Alfredo, Las Palmas de Gran Canaria. Madrid, Ed. Rueda, 1984 (2. ${ }^{a}$ ed. corregida y aumentada), 2 vols. (esp. vol. I: Primera Parte, cap. V: "El despertar de la ciudad a mitad del siglo xix", págs. 233 ss.); NoREÑA SALTO, María Teresa, Canarias: Política y Sociedad durante la Restauración. Las Palmas, Cabildo Insular de Gran Canaria, 1975, 2 vols. (para el contexto político reinante en la situación).

2 Además de la información aportada por las obras de Quintana Navarro, Martín Galán y Herrera Piqué, todas ellas citadas en la nota anterior, hay unos Informes elaborados por el ingeniero Juan de León y Castillo y enviados a la Real Sociedad de Amigos del País de Las 
comprendía que la ciudad requería para su funcionamiento y posible expansión de una infraestructura portuaria mejor cualificada y, sobre todo, de mayor abrigo. Así, el por entonces Ingeniero Jefe de la Provincia, Clavijo y Pló (o Pou), a la sazón ingeniero militar, pergeñó un primer esbozo de puerto ${ }^{3}$, pero ubicado en la idónea bahía de las isletas, a salvo de vientos y corrientes marinas. Sin embargo, no fue este ingeniero el encargado de realizar tan vasto y comprometido proyecto. Tuvo que ser el ingeniero Juan de León y Castillo (1834-1912) ${ }^{4}$, hermano del Marqués del Muni (Fernando León y Castillo), quien se ocupara de tan magna tarea. Su vida, a este respecto, se confunde con el levantamiento de esta importante infraestructura grancanaria ${ }^{5}$, puesto que, desde que sale de las aulas de la Escuela de Ingenieros de Caminos, Canales y Puertos (1857), empieza a pensar en una obra que - según dice- será como el hall de Gran Canaria, algo parecido a un recibidor o vestíbulo para los «turistas de salud" venidos del Norte europeo ${ }^{6}$; aunque sin olvidar, por supuesto, la vertiente mercantil o económica de la futurible construcción. Con ello, se sumaba a otros tantos autores, algunos incluso anteriores, que enfatizaban el puesto de escala o paso del Archipiélago en el moderno intercambio de mercancías por mar, derivado de la explosión del transporte marítimo. Alonso Quesada, con sus poemas, sería el ejemplo prototípico de semejante postura ${ }^{7}$. Sin embargo, pronto se suscitaron las primeras discordias sobre el avance teórico y, lo más importante, político, de la petición de un Puerto para la Gran Canaria; así, D. Fernando León y

Palmas, que evidencian la situación: a) Memoria presentada a la Sociedad... acerca del estado en que se hallan las obras públicas de esta Isla en fin de 1874 por el Ingeniero..., en Anales de la RSAPLP, 1874, págs. 65-73; b) Borrador para el Informe a la Real Sociedad, 1879, en Archivo Histórico Provincial de Las Palmas (AHPP) (Fondo Documental) Juan de León y Castillo (JLC), leg. 27, doc. 9; c) Informe de D. Juan sobre el estado del Puerto de La Luz y el de Las Palmas (entrada en la Real Sociedad: 11 de marzo de 1882), en AHPLP/JLC, leg. 25, doc. 2.

3 AHPLP/JLC, leg. 6, doc. 9 (1) (= Del proyecto del Ingeniero Clavijo para el Puerto de La Luz); ibidem, leg. 14, doc. 1 (1) (= Párrafos del Proyecto de muelle de Clavijo).

4 Sobre la figura y, sobre todo, el pensamiento de esta importante personalidad del acontecer histórico canario de fines de siglo, véase mi Memoria de Licenciatura, Ciencia y Política en el Pensamiento de Juan de León y Castillo, en prensa.

s Tanto es así que en el Escalafón de ingenieros de Caminos, Canales y Puertos (Madrid, Revista de Obras Públicas, 1900, 101), viene recordado, aparte de su condición de Jefe de Administración de Primera Clase, por el hecho de que cuando se alude a "Servicios y Situaciones", se cita, literalmente, "Puerto de La Luz" (pág. 4). (Para consultar este ejemplar impreso, véase, AHPLP/JLC, leg. 22, doc. 4).

6 Cfr. AHPLP/JLC, leg. 4, doc. 15 (= Sobre aprobación del Proyecto de muelle de abrigo y desembarco en La Luz, 1862).

7 De este modo, gran parte de su obra es un canto a la geografía especial del Archipiélago, reflejando en sus poemas la repercusión del influjo de las grandes casas inglesas en el seno de la sociedad isleña ("cielo de Londres sobre el Mar Atlántico"); cfr. QuESADA, Alonso, Antología poética. Barcelona, Plaza y Janés, 1981. 
Castillo, en un artículo publicado en el periódico Las Canarias, cuya redacción estaba en Madrid, profetizaba en un temprano 1863 la bonanza de una infraestructura portuaria ${ }^{8}$. Mas, su hermano, el ingeniero, le salió al paso, ya en los años finales de su vida, para desmentir el nulo papel o, por lo menos, el de simple ejecutor de un proyecto. Para ello, alegaba, en sus repetitivas memorias sobre los progresos desarrollados en la realización de las obras del Puerto de la Luz $^{9}$, que sus idealizaciones primarias u originales diseños se remontaban a 1862, un año antes del escrito de su hermano. El resultado de esta agria polémica fue, tristemente, el alejamiento de estas dos grandes personalidades de la historia decimonónica canaria, que reviste mayor complejidad si atendemos a la condición fraternal de los protagonistas. En desquite de ambos, hemos de referir que, según la moderna historiografía ${ }^{10}$, el Puerto de Refugio de La Luz es una obra solidaria, que no debe a una sola persona o un único factor su cumplimentación.

Todos estos datos, que aquí resumo someramente, son la historia general de un gran evento social, económico y, por qué no decirlo, tecnológico, cual es el Puerto de Refugio de La Luz. En cambio, otro semblante ponemos al descubrir la ínfima producción bibliográfica relativa a la misma ejecución del proyecto ${ }^{11}$. Quiere decirse que abundan, quizá sobremanera, los estudios sociológicos acerca de las razones populares y finan-

8 En concreto, el largo comentario laudatorio de las buenas condiciones de Gran Canaria para la construcción de una obra portuaria y sus importantes repercusiones sociales y económicas, data del 4 de mayo de 1863. Sin embargo, lo que ocasionó la posterior polémica fraterna fue el aireamiento del conflicto en los medios de comunicación, y, en especial, la aparición de un folleto anónimo, El puerto de la Luz en Las Palmas de Gran Canaria (Las Palmas, Tipografía El Diario, 1909), que reducía el papel de D. Juan a mero comparsa de las líneas políticas de su hermano. El tiempo no mitigó las consecuencias del debate, llegando D. Fernando León y Castillo, por medio de sus memorias, publicadas tras su muerte en 1918 (Mis Tiempos, Madrid: Sucesores de Hernando, 1921, 2 vols.), a concluir que uno de sus grandes logros en la política fue la construcción del Puerto de La Luz.

${ }^{9}$ Cfr. AHPLP/JLC, leg. 18, doc. 1 (= Orígenes del Puerto de Refugio de La Luz en Las Palmas de Gran Canaria, por LEón Y CASTILLo, Juan de, 1909; que consta de 299 páginas manuscritas, de las que 217 son anexos a la memoria). Sin embargo, la primera redacción se remonta bastante atrás (1891): véase AHPLP/JLC, leg. 6, doc. 9 (= Puerto de Refugio de La Luz. Antecedentes acerca de su proyecto y remate y ejecución hasta la fecha por...). Luego, iría poco a poco completándose (lbidem, leg. 14, doc. 1; leg. 22, doc. 8; leg. 23, doc. 5).

10 Cfr. Martín Galán, Fernando, «1852-1883: Antecedentes del Puerto de Refugio de La Luz», Aguayro, n. 146 (mayo-abril de 1983), págs. 4-9.

${ }_{11}$ Me refiero a los aspectos técnicos de la realización, que no han recibido ningún estudio detenido desde la propia ejecución. Por ejemplo, hay que agradecerle a Alfredo Herrera Piqué, en su obra citada (Primera Parte: cap. VI: «El último tercio del xIX. El Puerto de La Luz», págs. 273 ss.), que nos ofrezca los diferentes proyectos y planos del Puerto a lo largo de su dilatada historia; sin embargo, casi nada nos informa del sistema empleado en la construcción, aunque bien es verdad que no consulta los fondos del legado de los hermanos León y Castillo. 
cieras de la vindicación de un Puerto, sin embargo, poco es lo que hay, verdaderamente, de descripción o explicación - menos aún, análisis- del sistema empleado en la construcción del Puerto de La Luz. En este sentido, el profesor Quintana Navarro, en su antaño Memoria de Investigación, editada en $1985^{12}$, habla de influencia británica en los sistemas y técnicas de realización de la obra, citando a empresas inglesas y a ingenieros canarios que corroboran tal huella ${ }^{13}$. Con todo, no hay un pleno detallamiento de los planes y confines teóricos de la obra, debidos a la mano de D. Juan de León y Castillo.

Por todo ello, hemos puesto nuestra atención en los planteamientos originales de este ingeniero; proponiéndonos, en este espacio, dar cuenta, siquiera en brevedad, de la naturaleza del sistema practicado por D. Juan en el Puerto de La Luz. De las mismas palabras vertidas por el ingeniero, sabemos que «su» sistema es el mismo que, originalmente, utilizaron los ingenieros ingleses Mr. Dixon y Mr. Parker (o Parkes) en distintas partes del Imperio británico, con dispar resultado ${ }^{14}$. De este modo, el primer proyecto, verificado en tierras de la India, concretamente en Karachi, parece que disfrutó de una postejecución óptima; cosa que no ocurrió en la escocesa localidad de Aberdeen, donde estos ingenieros ensayaron por segunda vez este sistema, ya que los problemas surgieron de la caída de los cubos hacia adelante por el excesivo presionar del aire comprimido entre las junturas de los bloques. Parece ser, además, que D. Juan se puso en contacto con los ingleses para asesorarse sobre estas «molestias" o defectos congénitos del sistema en sí, según se desprende de un documento conservado en el Fondo Documental de Juan de León y Casti$110^{15}$

Como quiera que sea, el sistema británico de D. Juan, al que llamaremos «Sistema de paramentos verticales», se caracteriza en lo técnico por las siguientes directrices: físicamente, es un sistema que evita la re-

12 Cit, véase nota 1.

13 Sobre el influjo británico son insoslayables las obras del profesor grancanario, MORALES LEZCANO, Víctor, "Inversiones inglesas en Canarias durante el siglo XIX», Moneda y Crédito, CXVIII (1971), págs. 101-121; "Capitalismo industrial e inversiones extranjeras en Canarias: 1850-1945", Anuario del Centro Asociado de la UNED de Las Palmas, V (1979), págs. 143-162; Los ingleses en Canarias (Iibro de viajes e historias de vida). Las Palmas, Edirca, 1986. Y también algún que otro artículo de HERRERA PIQUÉ, Alfredo, «La colonia inglesa en Gran Canaria: una gran aventura económica en el siglo xix», Aguayro, n. 94 (diciembre 1977), págs. 6-9.

14 En un artículo suyo, publicado en La Ciudad, del 28 de Julio de 1908. Además, véase AHPLP/JLC, leg. 28, doc. 13 (1872: estado del puerto de Karachi según el ingeniero W. Parkes).

${ }_{15}$ Cfr. AHPLP/JLC, leg. 24 , doc. 2 (= 3 cartas y dos pliegos con varios croquis de las obras de Aberdeen y propuestas de posibles soluciones técnicas al Dique del Puerto de La Luz, enviados por Mr. Parkes y Mr. Dixon entre los años 1886 y 1888). 
sistencia «dura» del dique con respecto al mar, puesto que el establecimiento en hilera de los cubos, dejando un hueco en la mitad justamente, hace que el agua entre y fluya a lo largo del tubo practicado, no forzando el choque directo con el entramado de los prismas; por otra parte, al no llevar cemento hidráulico en las juntas de los bloques -es decir, son dispuestos unos sobre otros sin mayor problema-, puede ocasionar un leve movimiento o, aun, descascarillamiento del «concreto» superficial del prisma; algo a tener en cuenta con el paso del tiempo, como pudo comprobar D. Juan el mismo año de entrega de la obra a la Autoridad (19023), cuando el Inspector Jefe corrió visita y evidenció este problema, designándolo como "catarro crónico» del sistema ${ }^{16}$. Una tercera característica ténica, y esta sí que es peligrosa, es la posibilidad de auténtica "explosión» de los bloques, a causa, como decíamos antes, del doble factor vacio-aire comprimido en el interior del hueco entre bloques, coadyuvado por la total ausencia de junturas.

Estas características del Puerto, no siempre recordadas convenientemente, incluso por los propios ingenieros, no describen de por sí al completo una obra con semejante sistema de construcción. Tampoco podemos olvidar el hecho notable de que la gran obra portuaria mereció el aplauso general de la profesión, amén de un extenso artículo en la recién fundada Revista de Obras Públicas (ROP) ${ }^{17}$, en el año de 1853, que valoraba en apreciativos términos tanto el sistema de construcción empleado y el resultado final conseguido, no menos que la economía de la ejecución, desarrollada durante un período dilatado de 20 años. Hay que decir, por tanto, que los «Paramentos Verticales» es un método práctico, eficaz

16 La Ciudad, 28.VII.1908, artículo, «La reforma del Puerto de La Luz»: «El ilustre ingeniero Sr. López Navarro, Inspector del Cuerpo, me dijo (a D. Juan) que el Dique no tenía enfermedad grave, que sólo padecía de un leve 'catarro crónico' que se curaría con un medicamento ideado por un ingeniero inglés, que se estaba aplicando a todos los de este sistema». Tal "medicamento" no era otra cosa que unas inyecciones de mortero y argamasa en las juntas de los bloques, véase AHPLP/JLC, leg. 13, doc. 1 (:- Borradores de la memoria «Reparación del Rompeolas del Puerto de Luz. Diversas soluciones», 1909); ibidem, leg. 22, doc. 2. Por otra parte, el ingeniero inventor del sistema, William Parkes, confiesa: «El abrir y cerrar de la junta longitudinal por la acción del mar es un resultado natural del modo de construcción adoptado y como yo dije en mi informe a los Sres. Dixon y Horne con fha. $1 .^{\circ}$ Stbre. ulto. es una cosa que debe impedirse pues si se deja continuar afectará últimamente la estabilidad del Dique" (en: AHPLP/JLC, leg. 24, doc. 2 [ carta de W. Parkes a D. Swanston, y seguramente traducida por él al español, del 15 de marzo de 1888]).

17 Véase AHPLP/JLC, leg. 27, doc. 18 (= anexos para la Memoria Orígenes del Puerto de Refugio...), en el que hay una copia manuscrita de «El Puerto de Refugio de La Luz», artículo publicado por la Revista de Obras Públicas, en 1882. Acerca de la fundación de la ROP, cfr. Mañas Martínez, José, «D. Eduardo Saavedra y Moragas», en: Asociación de Ingenieros de Caminos, Canales, y Puertos, Conferencias, 1983, s.f., s.l., págs. 25-49, esp. 35-6. 
y económico de realizar una infraestructura portuaria. Práctico porque, en primer lugar, hasta la fecha no ha necesitado de mayores inversiones para mantenerse en pie, y, lo que es más, los problemas vaticinados tanto por el dúo Dixon-Parker, e incluso por D. Juan, no han tenido mayor relevancia técnica. Éste es un aspecto no siempre recordado, puesto que algunas obras contemporáneas (p. e., los puertos de Gijón y Barcelona), se vieron necesitadas de urgentes partidas presupuestarias no ya para su reparación sino aún la propia reconstrucción total ${ }^{18}$. Eficaz en la medida que evita problemas notorios de índole física, esto es, la «física blanda» del sistema reconoce que la mejor defensa contra una fuerza constante y rebelde, como pueda ser la del oleaje, reside en el dejar pasar o, cuando menos, no resistirse estúpidamente a la fuerza del mar, provocando efectos no deseados y muy gravosos a la economía. Económico, finalmente, porque su sencilla ejecución, aunque requerida de grandes grúas y aparejos terrestres ${ }^{19}$, impide que el presupuesto se dispare insensiblemente. Esta última perspectiva estuvo presente, de manera constante, en la mente de D. Juan, atento conocedor de la pobre dinámica de las Obras Públicas en España, y más, si cabe, en la periferia ${ }^{20}$.

En fin, Paramentos Verticales es la denominación de un sistema constructivo verificado con éxito en el Puerto de Refugio de Las Palmas durante el final del siglo pasado; que debe su nombre no a las virtudes intrínsecas de su configuración, sino a la apariencia externa que ofrecía al observador.

18 Cfr. Tortella, Gabriel, «Primera Parte: La economía española, 1830-1900", en VV. AA., Revolución burguesa, oligarquía y constitucionalismo, (1834-1923), tomo VIll de la Historia de España. Barcelona, Labor, 1981, dirigida por Tuñón dE LARA, Manuel, págs. 115 ss. (transporte marítimo: inexplicablemente se omite cualquier referencia al Puerto de La Luz).

19 Cfr. Moreno CiRilo, J., De los Puertos de La Luz y Las Palmas y otras historias. Las Palmas, Gabinete Literario, 1947.

${ }_{20}$ Una prueba palpable de este conocimiento profundo de la situación de las obras públicas, por lo menos, en las Canarias y en lo que respecta a construcciones portuarias, la hallamos en un breve informe, Reseña histórica de sus puertos (Provincia de Canarias), Años de 1873 a 1881, conservado en: AHPLP/JLC, leg. 24, doc. 1. (Para un reconocimiento contemporáneo y general del estado de la cuestión, véase: Alzol.a y Minondo, Pablo, Las obras públicas en España. Bilbao 1899). 


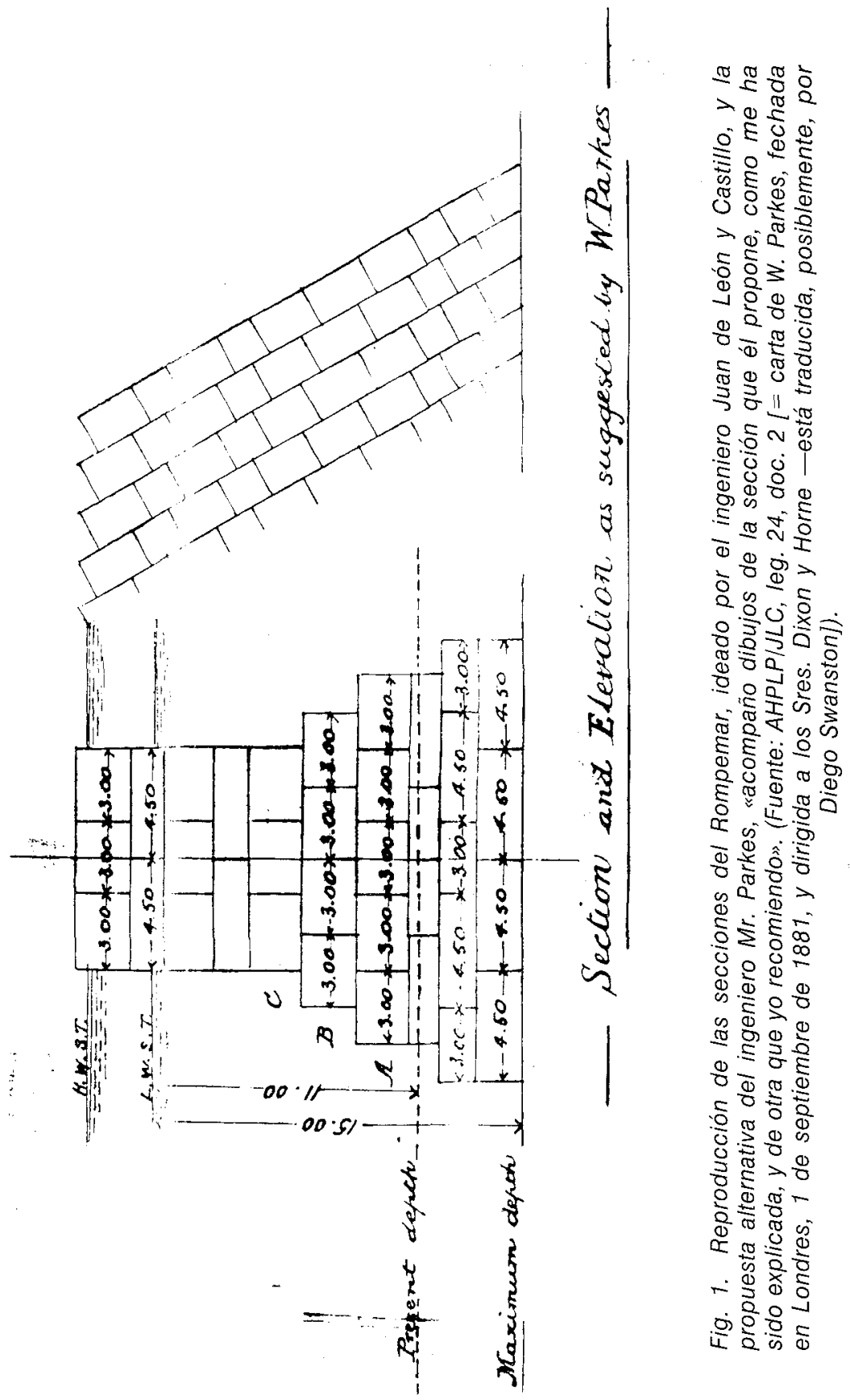




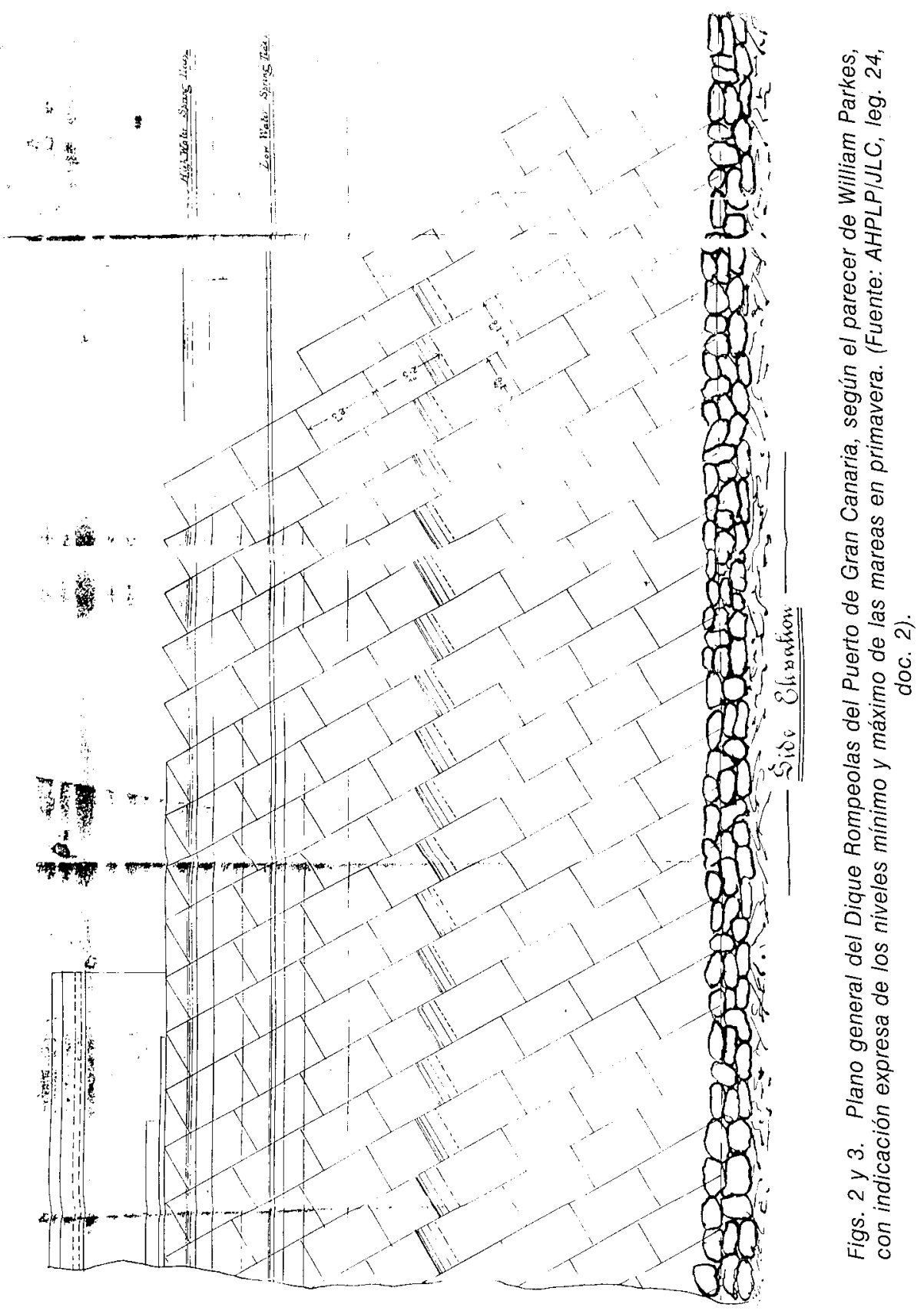




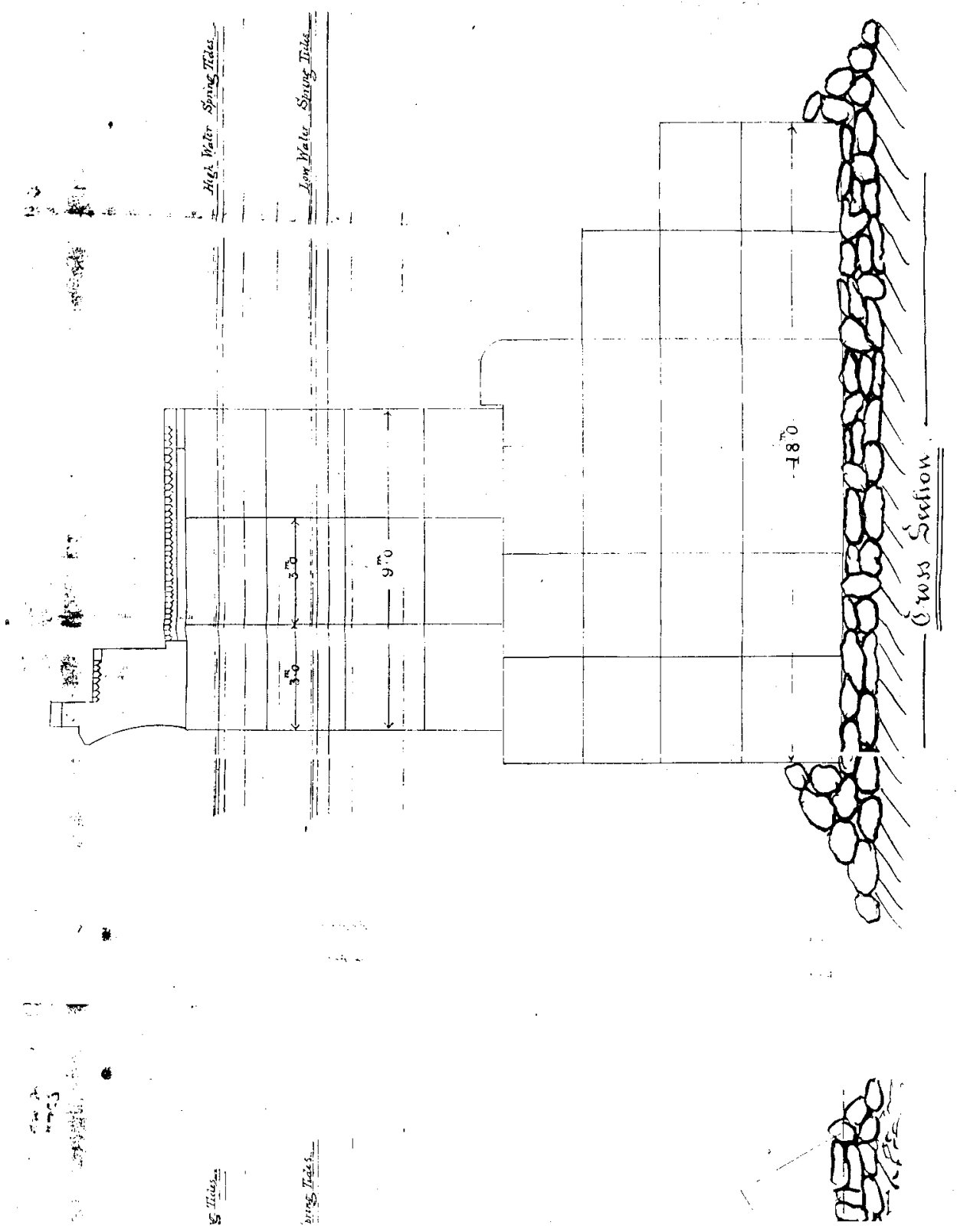

Fig. 3. 


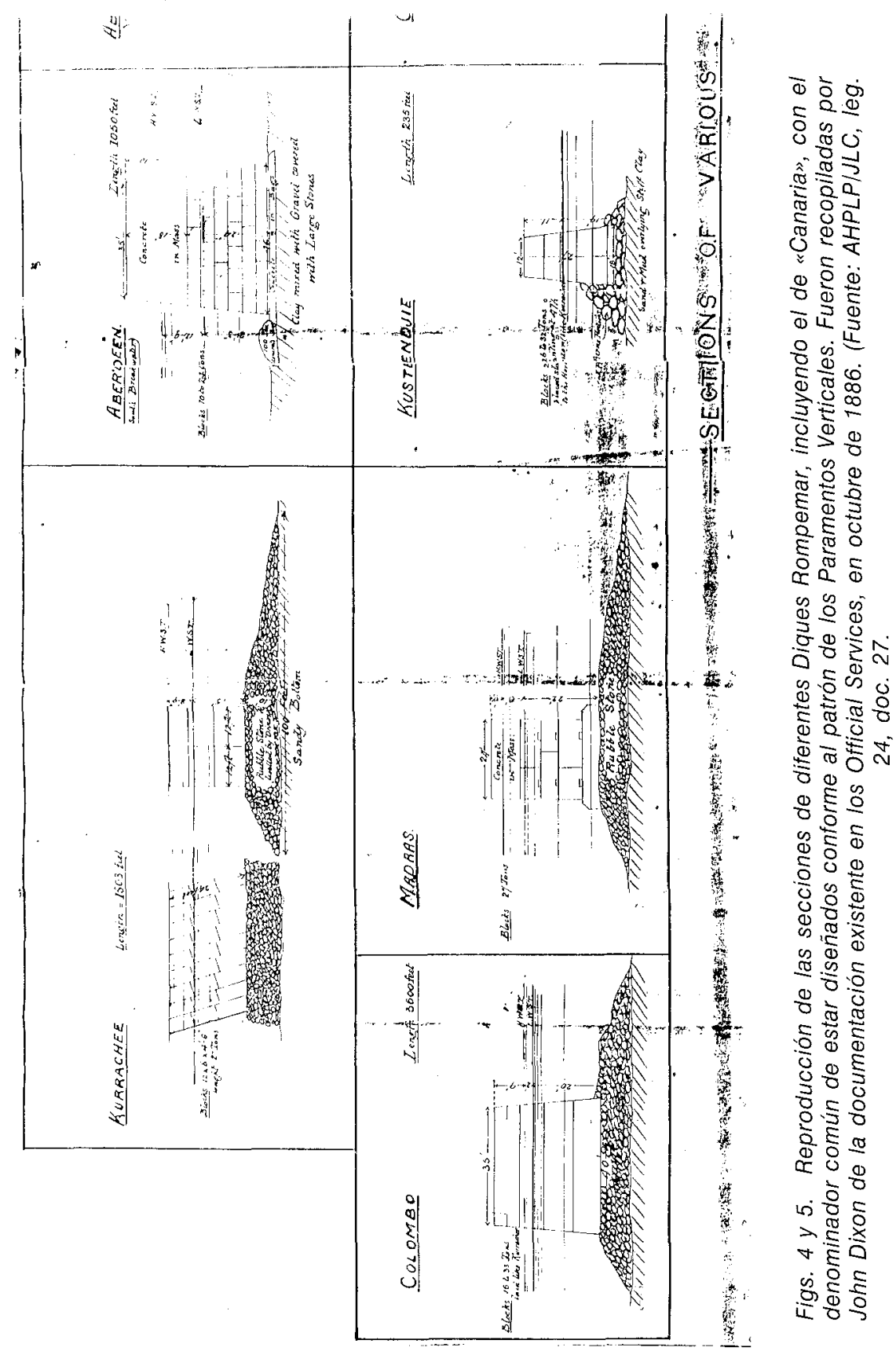




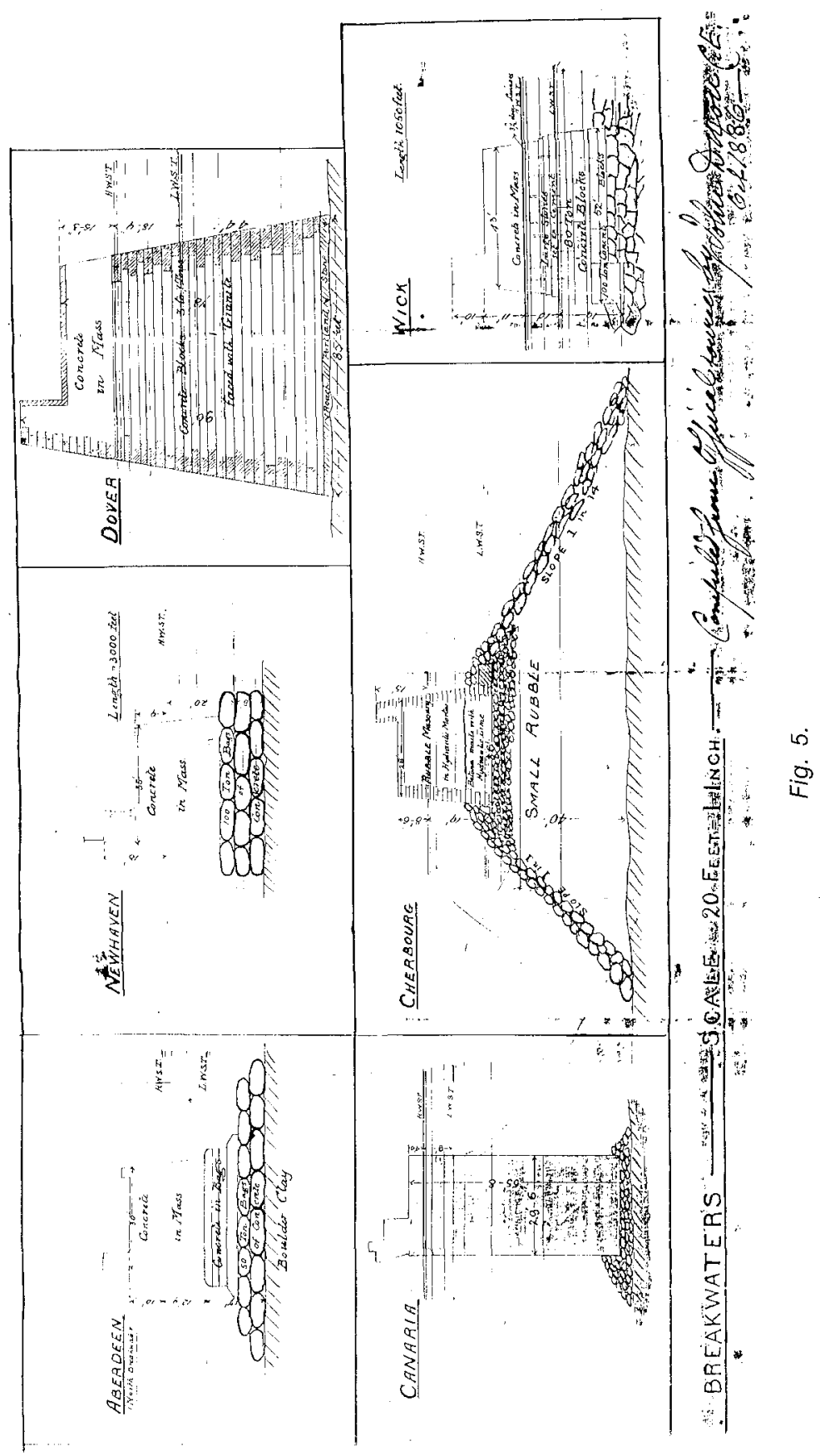

